\title{
Ein Sportstüick
}

Erhard Taverna

Im vollbesetzten Theater an der Sihl haben sich die Hochschule für Musik und Theater mit dem Schauspielhaus und den Zürcher Festspielen zur sportlichen Olympiade vereinigt. Geboten wird Elfriede Jelineks «Ein Sportstück» als Aerobic-Opera zu Techno, Gitarrenriffs und Navy-Chören, eine athletische Höchstleistung aus Tanz, Kampf und militärischem Drill. Das gekürzte Antisportpamphlet der Autorin wird mit grösstem Körpereinsatz hervorragend umgesetzt. Alles stimmt: die Choreographie, der kahle Betonkasten, die Klangmontagen und die raffinierte Spiegelung durch Videokameras. Die Schauspieler stampfen rhythmisch und formieren sich in Kolonnen, zu allem entschlossen. Sie skandieren im Chor die Sprachtiraden und Monologergüsse, die Botschaft vom sportiven Massenmenschen, der kranken Geistes in seinem kranken Körper, gleichzeitig Täter und Opfer ist.

\section{«Tobsuichtig ...}

Die aufgereihten Textblöcke sind auch lesend schwierig zu verstehen. Ausufernde Collagen, gespickt mit Anspielungen, ein Sprachgeflecht aus verzweifelter Anklage und ironischen Brechungen. Formulierungen, die hängen bleiben: «Mein Sohn will dem Tod zuvorkommen, indem

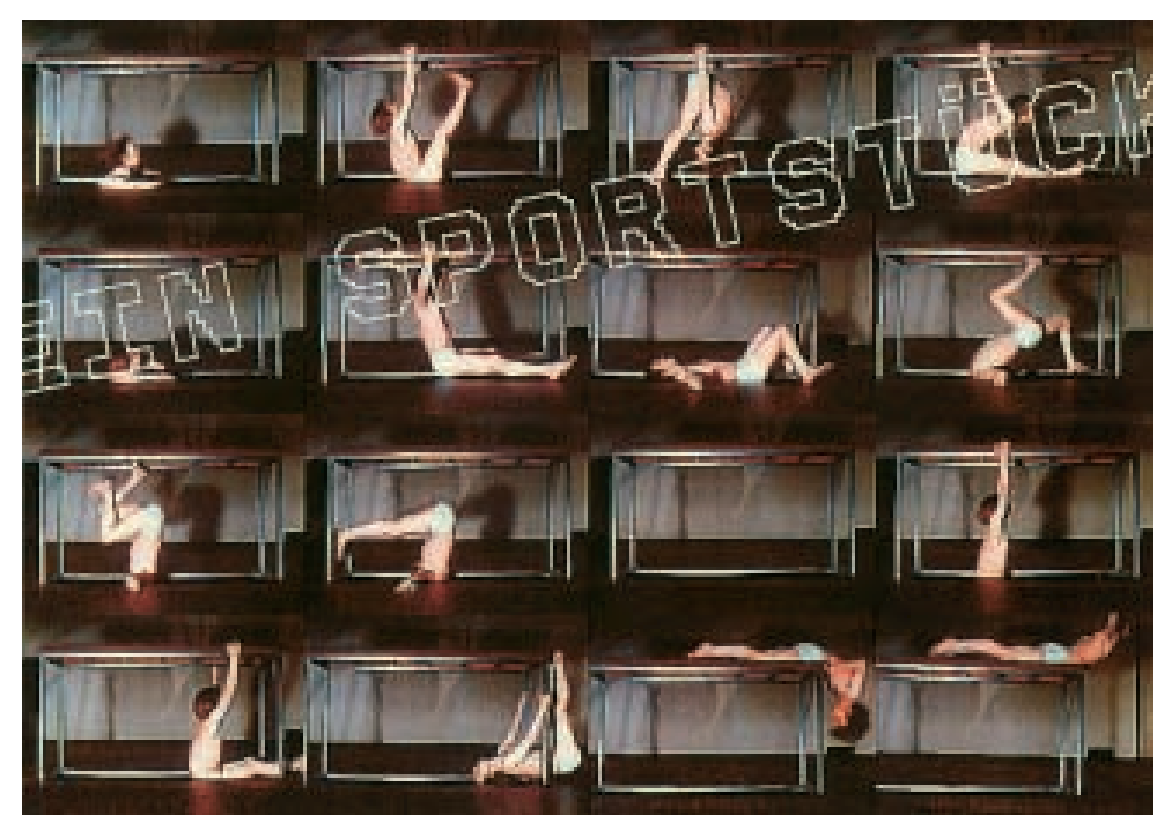

er sich einer Mannschaft anschliesst - Sportler sind wie Soldaten, ein jeder legt sein Bestes ins Trikot - denn ein Sportler ist, im Gegensatz zu Frau und Gott, nur was er tut - über mich weiss ich leider noch nichts, muss warten, bis mein Vorbild auf dem Bildschirm erscheint unter dem Einfluss des Sports fühlen sich Menschen plötzlich massgeblich, das ist ihr Wahn.» Jelinek sieht im Sport der Vereine und Gruppen eine Vorstufe zum Krieg. Indem Sportler und Sportlerinnen den eigenen Körper vergewaltigen, werden sie zu Kriegern. Spielregeln sind sanktionierte Gewalt, der Sport ein Synonym für Hooligans und Bürgerkriege, die Artikel von Adidas, Nike und Reebok die Uniformen der Schläger. Die Fitnessidiotie rentiert, nur der Sieg zählt, nicht die Fairness, es wird gedopt, geschmiert und verkrüppelt. Frauen kommen vor, als dümmliche Groupies oder enteignete Mütter, weil ihnen die Kinder beim Training abhanden kommen. Gegner Jelineks, es sind bei dieser Radikalität eine ganze Menge, beschimpfen die Autorin gerne als «Hohe Frau des Weltekels». Gewiss überzeichnet sie, doch so falsch ist ihre Analyse nicht. Die Ästhetik der Massenaufmärsche ist verführerisch, die Clique der Sponsoren und Funktionäre ist ein Rad im techno-sportiven Industriekomplex, die Ideologie des «fit for fun» ein unverzichtbarer Motor unserer Wirtschaft, die uns zu Voyeuren von Gladiatorenkämpfen macht. Die Schriftstellerin reagiert sensibel, wie ein Seismograph, aber nicht ohne Selbsterkenntnis: «Mir ist bewusst, dass diesem übersteigerten Moralismus nichts gerecht werden kann. Und mir ist bewusst, dass ich da besessen bin und auch ungerecht. Aber deshalb mache ich ja auch Kunst. Wenn ich Ausgewogenheit und Gerechtigkeit vermitteln wollte, wäre ich vielleicht Anwältin oder Ärztin oder Lehrerin. Ich bin im Grunde ständig tobsüchtig über die Verharmlosung.»

\section{... über die Verharmlosung»}

Der Fluch scheint aufgehoben, wir arbeiten nicht mehr im Schweisse unseres Angesichts. Doch die Wandlung vom Arbeits- zum Freizeitkörper verlangt Kompensation. Wir sehnen uns nach neuen Intensitäten. Vom Körper als Baustelle und Visitenkarte neuer Inszenierungen 
profitieren die Mediziner an vorderster Front. In der technisierten Welt wird ausgerechnet der anfällige Leib zur letzten Bezugsgrösse. Dank Sport sind wir noch anwesend, wer schwitzt, der ist. Die Topklassierten sind Vorbilder, im Wettkampf fühlen wir uns den Maschinen überlegen. Abenteuer- und Extremsportarten rufen eine Natur in Erinnerung, die am Verschwinden ist, sie vermitteln Lebendigkeit und kompensieren die Langeweile. Trendsportarten setzen erfolgreich die neuen Normen durch, alle sind dezent sexualisiert, labelbewusst, gesund und funktionsfähig. Der Hometrainer ersetzt die Ruhebank vor dem Haus. Wer dieser Fiktion nicht entspricht, gerät zunehmend in einen Beweisnotstand. Der traditionelle Turnverein hat einen schweren Stand, denn äusserlich sind wir Individualisten, jeder tut, was ihm passt, er joggt, sie skatet und beide fahren Mountainbike, gehen ins Fitnessstudio oder zum Langlaufmarathon. Vordergründig hat der Sport als vormilitärische Ertüchtigung ausgedient. Hat Jelinek trotzdem recht, wenn sie den neuen Helden und ihren Fans misstraut? Sie wittert im rekordsüchtigen Sekundentakt des Starrummels das alte Zeitmass: «Der völkische Staat muss von der Voraussetzung ausgehen, dass ein zwar wissenschaftlich wenig gebildeter, aber körperlich gesunder Mensch mit gutem, festem Charakter, erfüllt von Entschlussfreudigkeit und Willenskraft, für die Volksgemeinschaft wertvoller ist als ein geistreicher Schwächling» (Mein Kampf).

\section{Das Schwimmkonto}

\section{Hurni}

Dieser Sommer ist eine Hölle und meine Stossgebete an den Wettergott werden regelmässig überhört. Oder vermutlich von den Dankeshymnen der Sonnenanbeter übertönt, die es in viel grösserer Zahl gibt und die derzeit natürlich voll auf ihre Rechnung kommen. Wer jung und gesund ist, kann die Rechnung in mancherlei Hinsicht etwas anders machen. Ich bin zwar jung, aber habe MS und vertrage keine Wärme. Es braucht viel List und den einen oder anderen Lockvogel, um mich jetzt noch aus meiner klimatisierten Wohnung und meiner Lethargie $\mathrm{zu}$ locken. Freiwillig verlasse ich meine kühle Wohnung bei diesen Temperaturen nur mehr ungern. Ich fühle mich fiebrig und meine Beine scheinen auf dem heissen Asphalt kleben zu bleiben. Ich bewege mich wie in Zeitlupe. Wie wenn beim Fahrrad der Dynamo drin ist. Verlangsamung der Bewegung durch einen Widerstand, der Hitze heisst.

Im Wasser hingegen spüre ich meinen Körper dynamisch und ich komme mit Leichtigkeit vorwärts. Da fühle ich mich kräftig und mein Schwung greift. Das ist herrlich! Die körperliche Betätigung tut auch meiner Psyche gut, die bei dem vermehrten Hausarrest eindeutig leidet. Das Flusswasser ist zwar im Moment auch warm $\left(25^{\circ}\right)$, trotzdem bringt es ein bisschen Abkühlung, wenn ich eine Weile drin bleibe. Ich schwimme ausgiebig, denn erstens macht es mir grossen Spass, zweitens sammle ich Längen für mein Schwimmkonto und drittens hilft es, ein paar störende Kilos loszuwerden. Ich bin eine Person geworden, die sich für viele Aktivitäten unter gewissen Umständen überlisten muss. Bei diesen Temperaturen den Weg in die Badi unter die Füsse zu nehmen und in den Hitzestau eines Trams zu steigen, fällt mir äusserst schwer. Und allzu früh am Morgen schaffe ich es nie aus den Federn, denn ich habe Anlaufschwierigkeiten. Da ich ein simples Gemüt zu sein scheine und/oder einfach einen gewissen Ehrgeiz habe, genügt das Punkten als Motivation, mich in die Badi zu bringen. Bis jetzt habe ich knapp 300 Längen auf meinem persönlichen Schwimmkonto, das ich Anfang der Saison eröffnet habe. Wenn ich bei Badeschluss im Herbst mein Ziel erreiche, werde ich mich mit einem Geschenk belohnen. Welcher Art bin ich mir noch nicht schlüssig, was aber nichts macht, denn darüber denke ich beim Schwimmen gerne nach.

In der rhythmischen Bewegung des Schwimmens lässt es sich überhaupt sehr gut denken und träumen, finde ich. Ein wiederkehrender Tagtraum ist eine Kreuzfahrt in die Antarktis. Die immense, spärlich belebte Eislandschaft hat mich schon immer fasziniert und mittlerweile liebe ich ausserdem die Kälte über alles. Ich fahre nicht mehr häufig weg. Reisen ist mit vielen Unregelmässigkeiten und viel Unabschätzbarem verbunden und das leert den Akku schneller. Der vertraute und einigermassen berechenbare Rah- 